\title{
Research on Evaluation of the Efficiency of Internal Control of State Owned Listed Corporation Based on DEA
}

\author{
Shi Qiu, Hongqu He, Hongwei Guo, and Xi Huang
}

\begin{abstract}
Most listed corporations evaluated the effectiveness of internal control following the passage of the Sarbanes-Oxley Act of 2002(SOX) at the expense of the unprecedented assessment cost. But the quality of internal control rests with effectiveness and efficiency of internal control. Hence this paper puts forward the DEA method to evaluate efficiency of the internal control in China State-owned Listed Corporations. The empirical research finds that the efficiency value of internal control based on DEA method is fine generally except the wasting in the pure technology efficiency (PTE) and scale efficiency (SE). In addition, the DEA-based evaluation result is inconsistent with the DIB index, which is one of the predominant internal control indexes in China. Since these two strategies cannot be compared directly, we compare them with auxiliary of Tobin $Q$ by the similarity computation. The results indicate that the DEA index outperforms the DIB index from the perspective that the good internal control should improve the enterprises' value while the bad one would not.
\end{abstract}

Index Terms-Internal control, operational efficiency, DEA, Tobin Q.

\section{INTRODUCTION}

Listed companies were required to assess the quality of their internal control systems, which is always a high-profile issue to the investors and stakeholders given the financial fraud, especially for the State-Owned Enterprises (SOE). In the world top 500 corporations announced by the American Fortune magazine in 2015, there were 106 Chinese companies and the SOE accounted for $80 \%$. However, the defect of internal control had brought about great damage to the SOE. For example, the large losses of China National Aviation Fuel can be attributed to the speculation on financial derivative instruments and the huge waste of state-owned assets is blamed on the high price merger and acquisition. Therefore, after the enactment of SOX(Sarbanes-Oxley) Act of American in 2002, China has also began to establish the

Manuscript received May 24, 2017; revised October 27, 2017. This work was supported in part by National Natural Science Foundation of China (Grant No.61303043), Scientific Research Fund of Hunan Provincial Education Department (Grant No.13B142), Hunan Social Science Foundation of China (Grant No. 14YBA022),Hunan Provincial Philosophy and Social Science Foundation of China (Grant No. 14YBB007), Soft SCIENCE of Hunan Science and Technology Department(Grant No.2012ZK3001), Hunan Provincial Education Science '12th Five-Year' planning subject(XJK015QJG001).

Shi Qiu and Hongqu $\mathrm{He}$ are with the Bussiness School, Central South University, Changsha, Hunan, P. R. China (e-mail: 121601049@csu.edu.cn), Shi Qiu is also with the School of Economics and Management, Changsha University, Changsha, Hunan, P. R. China.

Hongwei Guo and Xi Huang are with the School of Economics and Management, Changsha University, Changsha, Hunan, P. R. China. standard system of internal control gradually, including the Basic Internal Control Norms of Enterprise in 2008 (BICNOE) and The Enterprise Internal Control Guidelines in 2010 (the Guidelines hereafter). In 2012, the Treasury and SASAC(State-owned Assets Supervision and Administration Commission) handed out the Notice on the accelerating the construction of internal control system. But the circumstance of failure in the internal control is very serious. In 2015, the National Audit Office of PRC audited 14 SOEs and found that there were 56 cases of violation of laws and disciplines and the false amount of revenue, profit and asset were 29.765billion, 19.357 billion and 4.291billion respectively. Hence the question on the implementation of the internal control institution of SOEs needs to be answered at first.

Therefore, this paper evaluates the internal control of SOEs based on DEA (Date Envelopment Analysis) method. In the evaluation, the proposed schema showed a better result than the DIB method, which is one of the predominant internal control indexes in China.

\section{RELATED WORK}

Most studies focused on the elements of internal control [1]-[3] or the extent of realization in the goal of internal control [4]-[6] to evaluate the quality of internal control. While the Xiamen University and Shenzhen DIB Company (the first company studying internal control in China) keep doing the research on the internal control index. However, the quality of internal control depends on the effectiveness and efficiency of internal control. The above mentioned researches mainly evaluated the effectiveness of internal control, and little work has been performed on the efficiency of internal control. Our research is motivated by the fact about the gradual increasing cost of assessing internal control. Lianhua L, et al. [7] provided the framework of theory and instruments of measuring and evaluating the efficiency of internal control. CHI Guohua, et al.. [8] also constructed a set of internal control quality evaluation index system and established the internal control index of listed corporations by integrating the 'elements', 'weakness' and 'targets' concepts of internal control. Nevertheless, there have been only a few attempts to evaluate the efficiency of internal control in theory, and no systematic attempts to the empirical research.

This paper is to study the efficiency of internal control of Hunan SOEs in 2013 using the DEA method by taking five elements of the internal control as the inputs and three targets of internal control as the outputs, and compare the result with the DIB index to discover the problems existed in the China SOEs, and make suggestions to improve the efficiency of internal control. 


\section{METHOD AND SAMPLE}

This paper designs five-inputs and three-outputs when utilizing the DEA approach to evaluate the efficiency of internal control.

\section{A. Input-indicators}

According to the COSO internal control framework [9], the internal control contains five elements of control environment (CE), risk assessment (RA), control activities (CA), information and communication (IOC) and monitoring (M). We use the DIB company information disclosure index database of internal control to reflect the inputs of the five elements. This index database has 5 first-level indexes based on the 5 elements of internal control, 30 second-level indexes and 87 third-level indexes. The CE's data range is 0 to 19 , RA's data range is 0 to 11 , CA's data range is 0 to 14 , IOC's data range is 0 to 6 and the M's data range is 0 to 16 . The higher the indexes are, the higher the cost of establishing the internal control will be. Therefore, the study chooses the above indexes as the input-indicators.

\section{B. Output-indicators}

On the basis of COSO internal control framework, internal control influenced by the enterprise's board of directors, managers and other people, is a process to provide sound assurance for realizing the goal of effectiveness and efficiency of operations, reliability of financial reporting and compliance with applicable laws and regulations. As a result, this work chooses following three output-indicators. The first indicator is Operation measured by the return on equity (net profit divided by net-asset) to reflect the effectiveness and efficiency of operations, based on the fact that the weight of return on equity (ROE) is the biggest weight and can show the operating ability best according to the enterprise comprehensive performance evaluation index and weight table of 'Implementing Rules for the Comprehensive Performance Evaluation of Central Enterprises' enacted by the SASAC [10]. Because the data of the DEA model should be all nonnegative, we normalize all the data by the following formula.

$$
\text { Normalized } R O E_{i}=\frac{R O E_{i}-\operatorname{Min}(R O E)}{\operatorname{Max}(R O E)-\operatorname{Min}(R O E)}
$$

where $\operatorname{Min}(*)$ and $\operatorname{Max}(*)$ mean the minimum and maximum value in the ROE set.

The second indicator is the report indicator reflecting the reliability of financial reports. Johnson et al. [11] have ever measured poor financial reporting quality by the absolute value of abnormal accruals. So, the study estimates the Reporting by the relative proportion of the absolute value of normal accruals to the sum of the absolute value of normal accruals and the absolute value of abnormal accruals [3]. The equation is as follow:

$$
\text { Reporting }=\frac{\mid \text { Normal Accruals } \mid}{\mid \text { Normal Accruals }|+| \text { Abnormal Accruals } \mid}
$$

Then the abnormal accruals are estimated via using the Modified Jones Model [12]. In this model, normal accruals are calculated as a function of the change in revenue minus change in accounts receivable and the level of properties, plants and equipments. These variables control for changes in accruals that are driven by the changes in the firm's economic condition. Total assets at the beginning of the year adjust all the variables in the model. The abnormal accruals are calculated by the below equation.

$$
\begin{aligned}
& T A_{\mathrm{it}} / \mathrm{A}_{\mathrm{it}-1}=\beta_{1}\left(1 / \mathrm{A}_{\mathrm{it}-1}\right)+\beta_{2}\left[\left(\Delta R E V_{\mathrm{it}}-\Delta \mathrm{REC}_{\mathrm{it}}\right) / \mathrm{A}_{\mathrm{it}}-1\right] \\
& +\beta_{3}\left(P P E_{\mathrm{it}} / \mathrm{A}_{\mathrm{it}-1}\right)+\mathrm{e}_{\mathrm{it}}
\end{aligned}
$$

where

$t=$ year2013,

$\mathrm{TA}_{\mathrm{it}}=$ total accruals for firm $i$,

$\mathrm{A}_{\mathrm{it}-1}=$ total assets for firm $i$,

$\mathrm{REV}_{\mathrm{it}}=$ change in net revenues for firm $i$,

$\mathrm{REC}_{\mathrm{it}}=$ change in accounts receivable for firm $i$,

$\mathrm{PPE}_{\mathrm{it}}=$ gross property plant and equipment for firm $i$, and $e_{\text {it }}=$ error term for firm $i$.

Total accruals are defined as income before extraordinary items minus operating cash flows. The error term of the regression model showed in equation (3.2) is the abnormal accruals (i.e., Abnormal Accruals). The normal accruals (i.e., Normal Accruals) are calculated as Total accruals subtract Abnormal Accruals.

\begin{tabular}{ccccccc}
\multicolumn{7}{c}{ TABLE I: DESCRIPTIVE STATISTICS } \\
\hline \hline Variables & $\mathrm{N}$ & Mean & Median & $\begin{array}{c}\text { Standard } \\
\text { Deviation }\end{array}$ & Min & Max \\
\hline CE & 31 & 8.1 & 9.35 & 3.65 & 0 & 12.8 \\
RA & 31 & 5.68 & 5.77 & 1.05 & 3.06 & 7.51 \\
CA & 31 & 8.91 & 9.34 & 2.77 & 0 & 12.84 \\
IOC & 31 & 1.96 & 2.23 & 1.1 & 0 & 4.87 \\
M & 31 & 13.58 & 14.13 & 2.2 & 4.02 & 15.38 \\
Operation & 31 & 0.0283 & 0.0502 & 0.113 & -0.4441 & 0.1277 \\
Reporting & 31 & 0.5363 & 0.5483 & 0.2222 & 0.0437 & 0.9216 \\
Compliance & 31 & 0.0003 & 0.0002 & 0.0003 & 0 & 0.0014 \\
\hline \hline
\end{tabular}

Data resource: DIB information disclosure index database of internal control

The third indicator is the compliance indicator reflecting the compliance with the applicable laws and regulations. O'Keefe et al. [13] found that the higher the audit fees paid by the company, the better the corporation abiding by the General Accepted Accounting Principles (GAAP).Thereby, we can measure the Compliance by the proportion of auditor's fees in total assets [4].

\section{Sample Data Sources}

We choose 31 Hunan SOEs in 2013 as research, after removing 2 unusual data from the 33 Hunan SOEs. The above mentioned data can be collected from DIB information disclosure index database of internal control and CNINF's annual report, internal control evaluation report and internal control audit report, etc.

\section{EMPIRICAL ANALYSIS OF THE EFFICIENCY OF INTERNAL CONTROL}

\section{A. Descriptive Statistics}

The Table I describes the distribution of five input-indicators and three out-indicators. The total score of 
CE index is 19 scores, and the mean value is 8.1 scores, minimum value is 0 and maximum is 12.8 scores, Standard Deviation is 3.65 scores. These scores show the control environment of Hunan SOEs is weak in general, and the gap among the enterprises is wide. The best ones barely meet the requirement and the worst ones don't disclose any information of control environment. The total score of RA index is 11 points while the true mean value is 5.68 points and reaches the half of the maximum score. This shows Hunan SOEs have the basic ability of risk assessment, identify, analysis and response. The total score of CA index is 14 points, and the actual mean value is 8.91 points and just qualified. The minimum value is 0 which indicates there isn't any control activities in Hunan SOEs. The total score of IOC index is 6 , minimum value is 0 and the mean value is 1.96 , all of which suggest the Hunan SOEs are not qualified in the IOC. The total score of $\mathrm{M}$ is 16 and the mean value is 13.58 , which show a good performance in the internal monitoring compared with the other four indexes. The listed companies' evaluation and auditing of the internal control are beneficial to monitoring the internal control.

The range of the three output-targets value is 0 to 1 . The Operation target is ROE and its mean value is $2.83 \%$. The ROE mean value of enterprises supervised by the SASAC is
$5.5 \%$ in 2013. The Hunan SOEs' operations don't catch up with the national average. As to the Reporting target, the mean and minimum values are $53.63 \%$ and $4.37 \%$ respectively, which indicate that the overall reliability of financial reports of Hunan SOEs is relative high and individual firms should make great efforts to improve the reliability of financial reports. Finally, the mean value of Compliance target is only $0.03 \%$, which shows that the extent of observing the laws and regulations of Hunan SOEs is very low.

In summary, through the analysis using DEA, we can get the result that the five input-elements of internal control in Hunan SOEs just reach the standard, but the three output elements are low qualified. The left question is how to evaluate the efficiency of internal control in the Hunan state-owned enterprises.

\section{B. The Efficiency Analysis of Internal Control by DEA Model}

At first, we analyze the efficiency of internal control of the 31 Hunan SOEs, and get the technology efficiency (TE), pure technology efficiency (PTE) and scale efficiency (SE). The results are showed in the Table II.

TABLE II: THE RELATIVE EFFICIENCY OF INTERNAL CONTROL IN LISTED COMPANIES

\begin{tabular}{|c|c|c|c|c|c|}
\hline Stkcd & Company name & 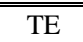 & $\begin{array}{l}\text { PTE } \\
\end{array}$ & 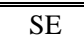 & Return to scale \\
\hline 000157 & zommlion & 0.928 & 0.937 & 0.991 & irs \\
\hline 000419 & Tongcheng Holdings & 0.952 & 1.000 & 0.952 & drs \\
\hline 000428 & Huatian Hotel & 0.937 & 0.952 & 0.984 & drs \\
\hline 000430 & Zhang Jia Jie Tourism & 1.000 & 1.000 & 1.000 & - \\
\hline 000548 & Hunan Investment & 1.000 & 1.000 & 1.000 & - \\
\hline 000590 & Tus-Guhan & 1.000 & 1.000 & 1.000 & - \\
\hline 000702 & Hunan Zhenghong Science and Technology & 1.000 & 1.000 & 1.000 & - \\
\hline 000722 & Hunan Development & 1.000 & 1.000 & 1.000 & - \\
\hline 000738 & AVIC Aero-engine Controls & 0.765 & 0.784 & 0.976 & irs \\
\hline 000748 & Greatwall Information Industry & 1.000 & 1.000 & 1.000 & - \\
\hline 000799 & Jiugui Liquor & 0.887 & 1.000 & 0.887 & irs \\
\hline 000819 & Yueyang Xingchang Petro-chemica Co. & 1.000 & 1.000 & 1.000 & - \\
\hline 000900 & Xiandai Investment & 1.000 & 1.000 & 1.000 & - \\
\hline 000906 & Zhejiang Materials Development & 0.772 & 0.789 & 0.978 & irs \\
\hline 000917 & Hunan TV and Broadcast Intermediary & 0.983 & 0.984 & 0.998 & drs \\
\hline 000918 & China Calxon & 0.821 & 0.901 & 0.911 & irs \\
\hline 000932 & Valin Steel & 0.766 & 0.832 & 0.921 & irs \\
\hline 600127 & JinJian Cereals Industry & 1.000 & 1.000 & 1.000 & - \\
\hline 600156 & Hunan Huasheng & 1.000 & 1.000 & 1.000 & - \\
\hline 600390 & Kingray New Materials Science and Technology & 0.775 & 0.786 & 0.986 & irs \\
\hline 600416 & Xiangtan Electric Manufacturing & 0.885 & 0.974 & 0.908 & irs \\
\hline 600458 & Zhuzhou Times New Material Technology & 1.000 & 1.000 & 1.000 & - \\
\hline 600476 & Hunan Copote Sci.\& Tech. & 1.000 & 1.000 & 1.000 & - \\
\hline 600479 & Qianjin Pharmaceutical Company & 0.958 & 1.000 & 0.958 & drs \\
\hline 600731 & Hunan Haili Chemical Industry & 0.778 & 0.840 & 0.926 & irs \\
\hline 600744 & Huayin Electric Power & 1.000 & 1.000 & 1.000 & - \\
\hline 600961 & Zhuzhou Smelter Group & 1.000 & 1.000 & 1.000 & - \\
\hline 600963 & Yueyang Forest and Paper & 0.833 & 0.892 & 0.934 & irs \\
\hline 600969 & Chendian International Development Share-holding Co. & 1.000 & 1.000 & 1.000 & - \\
\hline 600975 & New Wellful & 0.719 & 0.797 & 0.903 & irs \\
\hline \multirow[t]{2}{*}{601098} & China South Publishing and Media Group Co. & 1.000 & 1.000 & 1.000 & - \\
\hline & Mean & 0.928 & 0.951 & 0.975 & \\
\hline
\end{tabular}

Data sources: CNINF's network

Mean-average value; Peer -reference to similar scale companies;

irs- increasing returns to scale; drs-decreasing return to
General speaking, the company is DEA-efficient (DEA Validity) while both the PTE and SE are 1, otherwise the 
company is weak DEA-efficient (DEA Invalidity) when only the PTE or SE is 1 and is non DEA-efficient (DEA Invalidity) if the PET and SE are both not 1. From the table II, we find that there are 16 DEA Validity and 15 DEA Invalidity enterprises. This result indicates that half of the companies should optimize the efficiency of internal control. In addition, the mean value of the TE is $92.8 \%$, showing that the efficiency of internal control waste almost $7 \%$. The listed companies can improve the TE of internal control through improving the aspect of PTE and SE.

\section{The Comparison between the DEA Index and the DIB Index}

In order to analyze the performance of the two methods, we adopt the enterprise value to evaluate the effect of the two methods. Since internal control can optimize the capital structure and reduce the financial risk, thus it is expected to maximize the enterprise value by the good internal control [14], [15]. In addition, many researchers examined the relation between corporate governance and firm value, and found the good internal control is beneficial to the better performance and higher firm value [16], [17].

To get the enterprise value data, the Tobin Q (stated by the James Tobin in 1969) has been used to measure the firm value by many researchers around the world [18], [19]. Specifically, we calculate the Tobin Q of Hunan State-owned corporations via the following formula [20].

$$
\text { Tobin } Q=\frac{M V O S+M V N T S+B V L}{B V T A}
$$

where

MVOS - the market value of the firm's outstanding shares;

MVNTS - the market value of the firm's non tradable shares;

BVL - the book value of the firm's liabilities;

BVTA - the book value of the firm's total assets.

Above values can be retrieved in www.cninfo.com.cn.

Then, we can get the following information about the two evaluating methods and firm value (Table III). The table is arranged by DIB index order.

TABLE III: THE INFORMATION OF DIB INDEX, DEA INDEX AND TOBIN Q

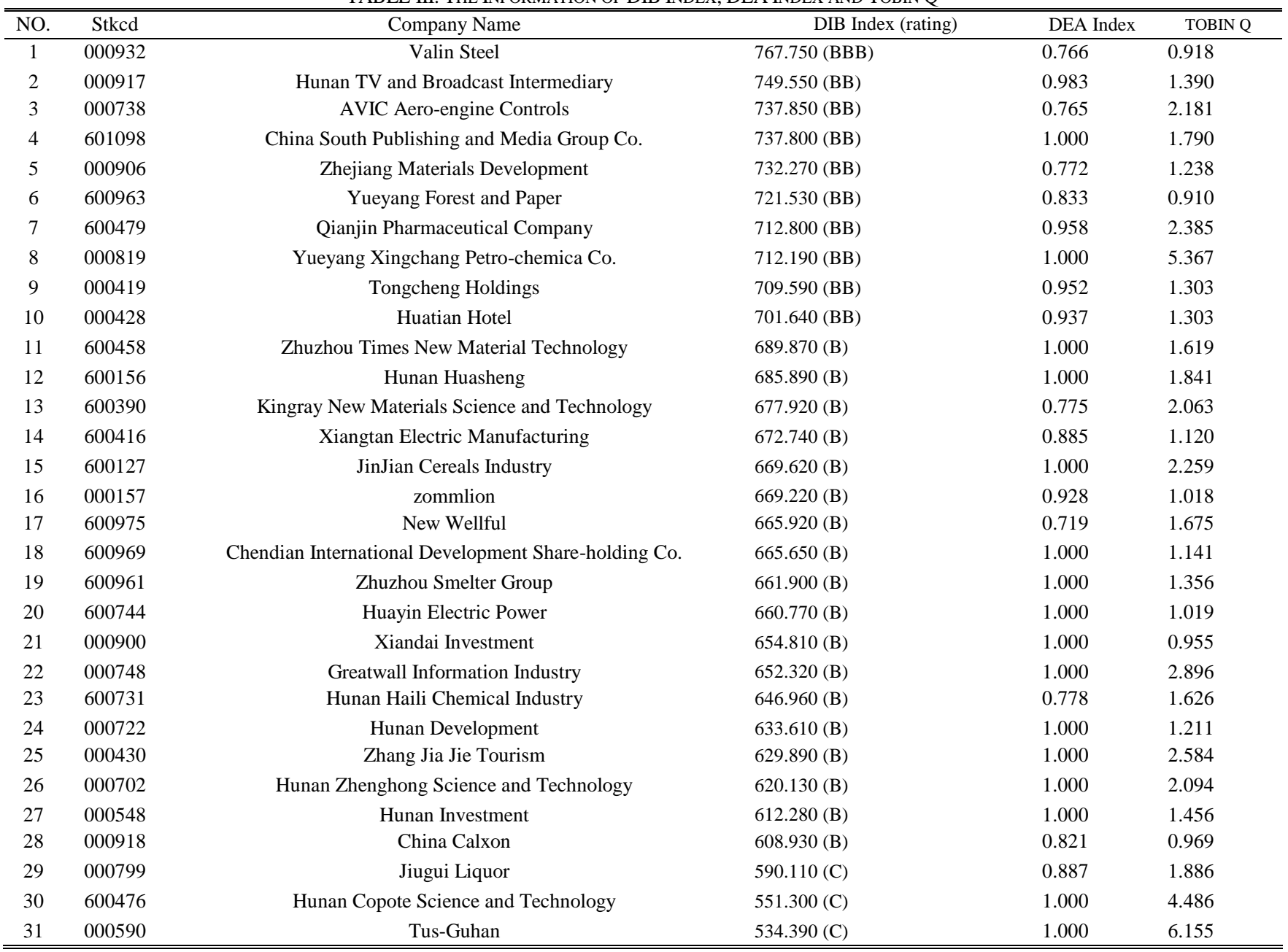

Data Resource: DIB Index (Rating) is obtained from DIB database

DEA Index is the TE value.

TABLE IV: THE ClASSIFICATION BY DIB, DEA INDEX AND TOBIN Q

\begin{tabular}{cccc}
\hline \hline Set Type & DIB Index & DEA Index & Tobin Q \\
\hline $\begin{array}{c}\text { High qualified } \\
\text { set }\end{array}$ & $\{1,2,3,4,5,6,7,8,9,10\}$ & $\{4,8,11,12,15,18,19,20,21,22,24,25,26,27$, & $\{2,3,4,5,7,8,9,10,11,12,13,14,15,161,17,18$, \\
Low qualified & $\{11,12,13,14,15,16,17,18,19,20,21,22,2$ & $30,31\}$ & $19,20,22,23,24,25,26,2,29,30,31\}$ \\
set & $3,24,25,26,27,28,29,30,31\}$ & $\{1,2,3,5,6,7,9,10,13,14,16,17,23,28,29\}$ & \\
\hline \hline
\end{tabular}


We compare the two methods on the premise that if the quality of internal control is good, the firm value should be high in most cases, and a bad internal control tends to decrease the firm value [14], [15].The similarity computation based on Loss Of Information (LOI) [21], [22], which is calculated by the following formula, is adopted in the comparison.

$$
\begin{aligned}
& \operatorname{SIM}(R 1, R 2)=1-\operatorname{LOI}(R 1, R 2) \\
& \operatorname{LOI}(R 1, R 2)=\frac{|R 1 \cup R 2|-|R 1 \cap R 2|}{|R 1|+|R 2|}
\end{aligned}
$$

where

$R 1=$ The set of firms classified by DIB index or DEA index

$R 2=$ The set of firms classified by TOBIN Q

To get the data of the $R 1$ and $R 2$, we divide all the firms into two sets, high qualified and low qualified, according to the follow procedures. First, we divide the above 31 firms into two groups by the rating of DIB index. The firms whose rating of DIB index is above the $\mathrm{BB}$ are high qualified set, the rest firms belong to the low qualified set. Secondly, we divide the firms into two sets by the DEA index. The firms are high qualified set if the DEA index of the firm is 1 , otherwise the firms are low qualified set. Thirdly, we divide the firms into two sets by the value of Tobin Q. The firms are low qualified set if the Tobin Q of the firm is lesser than 1, otherwise the firms are high qualified set (Table IV). In table IV, each number represents a corporation as shown in table III.

We can calculate the similarity between DIB index and Tobin Q, and DEA index and Tobin Q respectively (Fig.1). As depicted in the Fig. 1, we find the similarity of high qualified set between the DEA index and Tobin Q (70\%) is much greater than the one between the DIB index and Tobin Q (43\%), and the similarity of low qualified set between the DEA index and Tobin Q (32\%) is two times as mush as the one between the DIB index and Tobin Q (16\%). Thus the DEA index outperforms the DIB index according to the aforementioned premise.

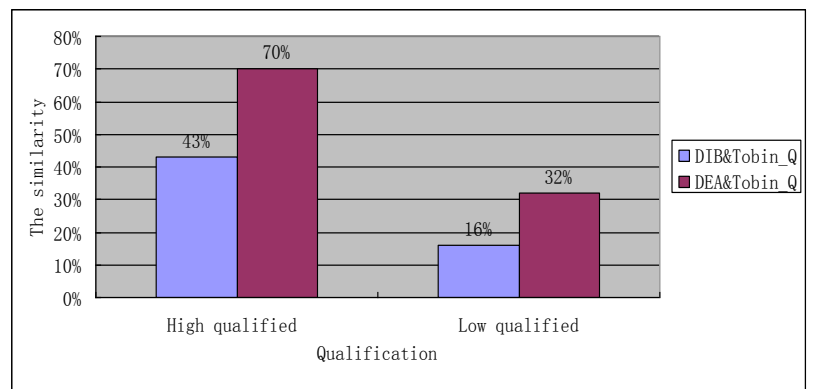

Fig. 1. The similarity between the internal control index and the Tobin Q.

It should be noted that the Tobin Q cannot be applied in evaluating the internal control directly because the high firm value does not necessarily mean a good internal control, and the low firm value does not necessarily mean a bad internal control for a corporation.

\section{CONCLUSIONS}

In conclude, the operating efficiency of internal control of Hunan state-owned listed companies is good in total, but many enterprises' pure technology efficiency (PTE) and scale efficiency (SE) are relative low. Accordingly, the enterprises ought to optimize the resource scale and configuration of internal control. At then, through comparing the similarity between DEA and the value of Tobin Q, we find that the classification based on DEA index is closer to the classification based on the Tobin Q than the one based on the DIB index. The main reason can be attributed to that the DIB version evaluates the outcomes of internal control execution, while DEA method evaluates the relative economical efficiency of internal control.

In conclusion, the enterprises should pay more attention to the DEA index of internal control, reducing the resource costs in the internal control while pursuing the target of internal control.

\section{ACKNOWLEDGMENT}

The authors would like to appreciate the anonymous reviewers for their constructive comments.

\section{REFERENCES}

[1] C. A. Botosan, "Disclosure level and the cost of equity capital," Accounting Review, vol. 72, no. 3, pp. 323-349, July 1997.

[2] T. Yan, M. Wang, and F. Xu, "Internal control, related party transactions and corporate value of enterprises directly controlled by Chinese central government," Journal of Chinese Management, vol. 1, no. 1, pp. 1-14, 2014.

[3] A. Mensah and B. Kwame, "Internal control information disclosure and corporate governance: Evidence from an emerging market," Corporate Governance, vol. 16, no. 1, pp. 79-95, 2016.

[4] C. Y. Tseng. "Internal control, enterprise risk management, and firm performance," University of Maryland, College Park, 2007.

[5] D. Rogier and W. R. Knechel, "Economic incentives for voluntary reporting on internal risk management and control systems," Auditing: A Journal of Practice \& Theory, vol. 27, no. 1, pp. 35-66, 2008.

[6] L. Bin et al., "Research on goal-oriented internal control index," Accounting Research, vol. 8, pp. 16-24, 2014.

[7] L. Li and G. Tang, "The efficiency of internal control: framework of theory and measure," Accounting Research, vol. 5, pp. 16-21, 2012.

[8] G. Chi and J. Guo, "Research on the internal control of listed companies based on the perspective of integration," Research on Financial and Economic Issues, vol. 8, pp. 75-82, 2015.

[9] COSO, Internal Control-Integrated Framework, 1992.

[10] State-owned Assets Supervision and Administration Commission of the State Council, "Implementing rules for the comprehensive performance evaluation of central enterprises," 2006.

[11] V. E. Johnson, I. K. Khurana, and J. K. Reynolds, "Audit-firm tenure and the quality of financial reports," Contemporary Accounting Research, vol. 19, no. 4, pp. 637-660, 2002.

[12] P. M. Dechow, R. G. Sloan, and A. P. Sweeney, "Detecting earnings management," Accounting Review, vol. 70, no. 2, pp. 193-225, 1995.

[13] T. B. O. Keefe, R. D. King, K. M. Gaver, "Audit fees, industry specialization, and compliance with GAAS reporting standards," Auditing, vol. 13, no. 2, pp. 41-55, 1994.

[14] L. R. Porta, A. Shleifer et al., "Investor protection and corporate governance," Journal of financial economics, vol. 58, no. 1, pp. 3-27, 2000.

[15] D. Yan, "Research on value chain accounting: Retrospect and prospect," Accounting Research, vol. 1, pp. 3-15, 2004.

[16] J. S. Hammersley, L. A. Myers, and C. Shakespeare, "Market reactions to the disclosure of internal control weaknesses and to the characteristics of those weaknesses under section 302 of the Sarbanes Oxley Act of 2002," Review of Accounting Studies, vol. 13, no. 1, pp. 141-165, 2008.

[17] L. Bebchuk, A. Cohen, and A. Ferrell, "What matters in corporate governance?" Review of Financial Studies, vol. 22, no. 2, pp. 783-827, 2009.

[18] C. E. Bai, Q. Liu, J. Z. Lu et al., "Corporate governance and firm valuations in China," Social Science Electronic Publishing, 2002.

[19] Y. Sun, "Internal control weakness disclosure and firm investment," Journal of Accounting, Auditing \& Finance, vol. 31, no. 2, pp. 277-307, 2016. 
[20] L. J. Xia and Y. Q. Fang, "Government control, institutional environment and firm value: evidence from the Chinese securities market," Economic Research Journal, vol. 5, pp. 40-51, 2005.

[21] E. Mena, V. Kashyap, A. Illarramendi et al., "Estimating information loss for multi-ontology based query processing," in Proc. the 13th Biennial European Conference on Artificial Intelligence (ECAI), 1998, pp. 78-92.

[22] M. Klusch, B. Fries, and K. Sycara, "Automated semantic web service discovery with OWLS-MX," in Proc. the 5th International Joint Conference on Autonomous Agents and Multiagent System, ACM, 2006, pp. 915-922.

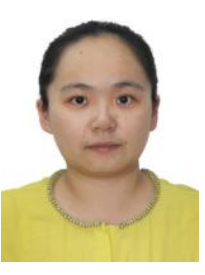

Shi Qiu was born in Hunan, China in Nov. 1984. She is a Ph.D candidate of management in the School of Business, Central South University, Changsha, China. The Master of accounting is in the School of Accounting, Hunan University, Changsha, China.

She is a teacher in the Department of Economics and Management of Changsha University, and meanwhile a fourth year $\mathrm{PhD}$ candidate majored in management from Central South University, Changsha, China. Besides, she has been working as a CPA. Her research interests include corporate governance, executive compensation and company internal control.

Shi Qiu is a member of The Chinese Institute of Certified Public Accountants. 